\title{
A utilização da máscara neutra na formação do ator
}

\section{Luciana Cesconetto}

Universidade do Estado de Santa Catarina

Este artigo é um resumo da dissertação que defendi no Programa de Mestrado em Educação e Cultura da UDESC ${ }^{1}$. A pesquisa consiste em uma exploração do fenômeno "utilização da máscara neutra na formação do ator".

A máscara neutra é uma máscara que se pretende inexpressiva, sem definição de gênero ou caráter. Esse objeto, denominado a princípio de "máscara nobre", foi utilizado pela primeira vez com fins pedagógicos na formação do ator por Jacques Copeau, no início do século XX. Foi um recurso encontrado por Copeau principalmente para eliminar as possibilidades de expressão facial do aluno-ator a fim de explorar as possibilidades do seu corpo como um todo em movimento. O termo "máscara neutra" foi introduzido por Jacques Lecoq, um pedagogo que continuou e aprofundou a estratégia de sua utilização.

A primeira parte do trabalho consiste em uma pesquisa bibliográfica. Verifiquei a teoria teatral de Jacques Copeau, contextualizando-a historicamente, a fim de identificar como foi possível o surgimento dessa prática. Investiguei também os desdobramentos da proposta inicial de Copeau, com relação à máscara neutra. Na segunda parte descrevo a prática com a máscara neutra desenvolvida pelo grupo de teatro Moitará (Rio de Janeiro). Na terceira parte comparei a proposta prática desse grupo com as propostas dos pedagogos estudados, identificando semelhanças e diferenças (a comparação ficou mais direcionada ao trabalho desenvolvido por Copeau). Nas considerações finais, sintetizei as constatações feitas, levantei questões que merecem ser investigadas e elaborei respostas provisórias.

\section{Considerações sobre a utilização da máscara neutra na formação do ator (Jacques Copeau)}

Copeau foi um dos fundadores da Nouvelle Revue Française e a partir de 1910, tornou-se crítico teatral da revista. Através desse ofício, conheceu o sistema teatral baseado nos papéis de vedetes e os exageros do naturalismo.

${ }^{1}$ Trabalho orientado pelo prof. José Ronaldo Faleiro 
Como crítico, rejeitou o naturalismo, corrente estética que prescrevia para a cena a reprodução cinematográfica do real. Copeau afirmava que o naturalismo, por trabalhar com o excesso de detalhes no palco, não exigia do ator o máximo de sua capacidade expressiva e não permitia à platéia explorar ao máximo sua capacidade imaginativa. Copeau rejeitou também o sistema de vedetes que surgiu no século XIX, o teatro de grandes atores com personalidades marcantes. Afirmava que esses atores eram cabotinos, falsos, estavam preocupados apenas com o sucesso pessoal.

Não satisfeito em criticar o que se fazia como teatro, resolveu construir, ele mesmo, uma outra possibilidade para a cena. Defendia que, para realizar uma renovação, era preciso primeiro construir uma escola para formar os novos atores, os quais viabilizariam um novo teatro. Copeau não conseguiu realizar seu projeto nessa ordem, fundando inicialmente o teatro do Vieux-Colombier, em 1913. No projeto de renovação teatral proposto por Copeau, o corpo do ator ocupava um lugar privilegiado.

\section{A teoria teatral de Jacques Copeau}

Para Copeau, o teatro é um meio de nos religarmos entre nós( 1993). Por isso, seria preciso que o teatro fosse compreendido, para que pudesse se tornar alimento de todos. Copeau buscava o "fundamental", o que está nas origens. Assim, chegou ao teatro popular. Encontrou na Commedia dell'Arte a força para combater a decadência do teatro de seu tempo, visto que nesse gênero teatral o foco não era a voz, mas o ator em ação como um todo; a cena era pobre em recursos materiais e os atores ricos em meios expressivos; não havia a preocupação com a representação realista; além do que nesse tipo de teatro o ator também era cantor, músico, malabarista, equilibrista e se relacionava com a platéia.

A busca da simplicidade estava na base do projeto teatral de Copeau. A economia de meios daria espaço para a poesia, para a ação dramática. Dentro dessa perspectiva, ele propôs para a cena o "palco nu”. Suprimiu o móvel e os painéis pintados e os substituiu pela arquitetura fixa, permanente. Reduziu os objetos da cena ao fundamental, ao que seria necessário para a ação dramática.

$\mathrm{Na}$ orientação do trabalho do ator, Copeau prescrevia os seguintes princípios éticos: trabalhar coletivamente; se fazer compreender; ser simples (alertava para o perigo da especialização técnica, do esvaziamento no virtuosismo); ser sincero (para ser sincero em cena, o ator deveria ser sujeito de suas 
ações, não deixar-se levar pelos modismos da cena. A primeira condição para ser sincero seria só interpretar textos que se admira. Só assim o ator poderia trabalhar apropriando-se desse texto, tornando-o seu); ter disciplina; acompanhar o crescimento do trabalho do colega; amar o teatro.

Copeau defendia que a palavra, em cena, deveria ser o resultado de um pensamento sentido pelo ator em todo o seu ser ( 1993:308). Para isso, o ator deveria admirar o texto e repassar pelo caminho do autor. Ao abordar a questão do corpo em movimento, Copeau prescrevia que o ator tivesse consciência da expressão do próprio corpo e uma boa técnica corporal.

\section{A escola do Vieux-Colombier}

Objetivando formar atores para a companhia do Vieux-Colombier, formar novos atores com o que Copeau chamava de uma "educação total", ele fundou, em 1921, a escola do Vieux-Colombier. A estrutura da escola compreendia o "Curso fechado" - ou Grupo de aprendizagem: destinado à formação de atores; o "Curso aberto": para complementar a cultura geral dos membros da cia. e de artesãos do teatro; e o "Curso livre": para espectadores e amigos do teatro. Abordo neste texto apenas o trabalho desenvolvido no Grupo de aprendizagem.

O embrião do método se formou em 1916, junto com Suzanne Bing (sua colaboradora pedagógica) a partir da observação do jogo das crianças (CHANCEREL, 1944). O método do trabalho prescrevia partir do silêncio e da imobilidade, para então, gradualmente, levar os alunos ao movimento e à utilização da voz.

O curso no Grupo de aprendizagem tinha a duração de três anos, ao longo dos quais trabalhavam as seguintes áreas de conhecimento: Educação corporal; Iniciação progressiva aos trabalhos manuais; Canto coral e individual; Exercícios de expressão dramática; Improvisação; Elocução, dicção, declamação; Cultura geral; História do teatro; Jogos livres (ou interpretações livres).

A área "Exercícios de expressão dramática" incluía: máscara, jogo do corpo, fisionomia e mímica. Um dos cursos chave da escola pertencia a essa área: era o curso de "Educação do instinto dramático": nesse curso iniciaram o trabalho sobre o estado neutro e preparatório e sobre a improvisação silenciosa com máscara inexpressiva.

O princípio de cobrir o rosto no trabalho pedagógico surgiu 
quandoCopeau tentou, um dia, solucionar o problema de uma aluna que não conseguia expressar os sentimentos de sua personagem em cena. Cobriu o rosto dela com um pano e o resultado foi positivo: a aluna relaxou e imediatamente expressou com o corpo todo o que lhe havia sido solicitado (CHANCEREL, 1944). Copeau resolveu então incluir esse recurso na formação dos alunos. Passou do pano a uma máscara que chamou de "nobre".

Chancerel (colaborador de Copeau) relata uma seqüência de exercícios com a máscara neutra: $\quad 1^{\circ}$ Tomar posição. - O jogador (...), deve se estabelecer, seus pés se apoiando solidamente no chão - se enraizar. Ele deve se sentir bem à vontade, livre dos seus movimentos, de ataque . $2{ }^{\circ}$ Colocar a máscara.- Segura-se a máscara com a mão esquerda, pelo queixo, a outra mão segurando o elástico, posicionado mais ou menos na altura das têmporas, que manterá a máscara no rosto.

Primeiro tempo: veste-se a máscara como um chapéu, o elástico se encontrando na altura da nuca. Segundo tempo, baixa-se a máscara sobre o rosto. Executar esses dois tempos sem hesitação.

$3^{\circ}$ Relaxamento - Uma vez mascarado, o ator deve se abandonar, se deixar, tornar-se 'disponível', pronto para receber nele o personagem que ele vai agir: uma espécie de pele dócil que espera seu hóspede. Os músculos devem estar flexíveis, relaxados, o espírito vazio, livre. (...). $4^{\circ}$ Nascimento da máscara. - A máscara toma consciência da sua existência. Jogo dos músculos do pescoço. Levantar a cabeça. Olhar. À direita. À esquerda. Olhar suas mãos. Seus pés. Se levantar. Andar.

Esse exercício elementar deve se manter elementar e ser muito curto. Não se trata de nada além de constatar as possibilidades de vida em si de uma criatura que não é você, de obedecer às suas instigações à medida que ela descobre as leis da sua própria existência, suas possibilidades, antes de cair na inconsciência"(CHANCEREL, 1944).

Com esses exercícios, pretendiam chegar ao corpo neutro, ao corpo descontraído. Seria um ponto de partida: o estado de calma, de repouso. Para ser neutro, o corpo teria que alcançar a despersonalização: seria uma forma de desnudamento que prepararia o ator para uma arte mais objetiva, seus movimentos seriam exigidos por essa máscara que substitui sua personalidade. 
Os outros exercícios que realizavam com a máscara eram os seguintes: familiarização com a máscara neutra; exercícios de mimo alegórico; simbolizar as formas plásticas: árvores, pontes (figuração ou técnicas mímicas); imitação das atividades e sentimentos humanos (figuração ou técnicas mímicas); imitar animais, estudo do comportamento dos animais (figuração ou tecnicas mímica); criação de pequenas cenas.

No que diz respeito à metodologia de ensino, Copeau propôs a cópia do real e não a cópia do modelo. Para imitar animais, iam em zoológicos observálos, desenhavam o que era observado, para depois representá-los com o corpo em movimento. Era uma estratégia para fugir dos clichês e da afetação. O aluno espectador deveria poder tirar, ele mesmo, indicações do que via, dos graus de inclinação da máscara, da direção do olhar.

Segundo Chancerel (CHANCEREL, 1944), a máscara contribui para combater no ator aprendiz sua tendência a gesticular; exige um grande domínio corporal, exige que todo o corpo atue. De acordo com Marinis (1995), a prática com a máscara neutra em Copeau contribuiu para ultrapassar a convenção pantomímica do gesto que traduz as palavras; desenvolver as qualidades dinâmicas do movimento, ritmo e intensidade; utilizar o princípio da independência articular e muscular do corpo; trabalharo princípio do raccourci: princípio da condensação da idéia, do espaço e do tempo; incentivar o aluno a ser autor do roteiro executado.

\section{Jacques Lecoq}

Dentre outros, Lecoq estudou com Jean Dasté (que foi aluno de Copeau), com quem aprendeu o trabalho sobre a máscara neutra. Desenvolveu uma escola em Paris, para a formação de atores, na qual a prática com a máscara neutra é um dos pilares pedagógicos. Segundo Lecoq, o corpo na neutralidade está em estado de alerta, de suspensão. Estar na neutralidade é se apresentaràs situações nas quais a gente se encontra em estado de calma, sem conflitos preliminares, nem idéias à priori. Estar disponível ao acontecimento, um pouco espantado, olhar de uma maneira ingênua, pronto para descobrir. $\mathrm{O}$ estado neutro suscita economia de movimentos (LECOQ, 1988).

Uma das regras ensinada por Lecoq é não deixar a máscara virada com o nariz para o chão, tocando no chão. Diz que essa posição é sinal de morte (LECOQ, 1988). Nota-se aqui uma sacralização da máscara, um respeito a algo misterioso escondido nesse objeto . 
Com relação à máscara neutra, os exercícios ensinados são: descoberta da máscara: experimentar a máscara, tocar, dizer o que sentiu; $1^{\circ}$ tema pedagógico - o despertar: como a máscara se acorda pela primeira vez; $2^{\circ}$ tema pedagógico: o adeus do navio; $3^{\circ}$ tema - a viagem elementar pela natureza: trata-se de uma viagem onde o aluno anda, corre, escala, salta por uma natureza calma, neutra, em equilíbrio; identificar-se com a natureza: o aluno torna-se os quatro elementos (água, terra, fogo, ar), torna-se diferentes matérias tais como madeira, papel, papelão, metal, líquidos; o método das transferências: tomam apoio nas identificações e transferem essas qualidades para a natureza humana. Quando Lecoq ensinava ele não dava muitas explicações aos alunos no início da aprendizagem. Preferia que descobrissem, eles mesmos, os recursos da máscara.

\section{Eldredge/ Huston}

Sears A. Eldredge e Hollis Huston são professores em universidades dos EUA. Em seus estudos, eles constataram que a definição de neutralidade varia de pedagogo para pedagogo e que existem diversos tipos de máscaras neutras. Eldredge diz que "os estilos de esculpi-las variam de acordo com a quantidade de personalidade considerada adequada para a máscara"(ELDREDGE - HUSTON, 1978). Em suas aulas, Eldredge ensina o seguinte:

- A contemplação da máscara. Trabalha com uma máscara de papel, só com buracos para os olhos e uma forma de cone para o nariz. Não há identificação de boca. A vantagem dessa máscara, segundo Eldredge, é que ela é mais abstrata, significa

simplesmente face humana. Os alunos observam e depois falam sobre as características da máscara: +verificam que ela é simétrica, não tem boca, não tem traços de personagem nem de emoção, não tem definição de gênero;

- Análise do movimento pessoal de cada aluno;

- Exercícios sobre o corpo neutro: levantar, andar, sentar;

- Exercícios sobre "a mente neutra": descobrindo o objeto pela primeira vez.

Com relação à metodologia de ensino, Eldredge discute a neutralidade a partir da resposta dos alunos à contemplação da máscara. 


\section{Elisabeth Pereira Lopes}

Autora da tese "A máscara e a formação do ator”(1990).Lopes em sua pesquisa, Lopes descreve e avalia a eficácia da máscara na formação do ator, passando pela máscara neutra e abordando outras máscaras. Ela informa que no período em que estudou o trabalho com a máscara na França, passou por experiências de transe e que voltando para o Brasil, ao ensinar o trabalho com máscaras, constatou que seus alunos também entravam em transe (experiências de eliminação da identidade, momentos em que a máscara "toma conta do corpo e da voz do ator"(1990)). Intrigada com o que ocorria, decidiu investigar o fenômeno. Fez uma pesquisa bibliográfica, entrando em contato com trabalhos de antropólogos que estudaram "o fenômeno do transe religioso com máscaras em sociedades não complexas”. Com as conclusões daqueles antropólogos sobre aquele fenômeno, a autora afirma que esclareceu o fenômeno que ocorria em sua sala de aula, no curso de teatro da Unicamp. De acordo com esse processo metodológico, a autora chegou às seguintes conclusões, dentre outras: em todo tipo de máscara, realista ou abstrata, existe um conteúdo sobrenatural associado à idéia do outro - o animal, o mito, o espírito; no trabalho com a máscara, um outro vai manifestar-se no corpo do ator se este não criar resistências emocionais durante o trabalho(LOPES, 1990).

\section{A prática com a máscara neutra no Brasil: o grupo Moitará}

Essa parte do trabalho consiste em uma breve descrição da oficina "o jogo da máscara”, ministrada pelo grupo de teatro Moitará ${ }^{5}$, em maio de 2000, durante o Festival Internacional de Londrina, na qual participei como aluna. Nessa oficina o ensino estava calcado em três tipos de trabalho: segmentações, ações (práticas corporais sem máscaras), e máscaras (neutra e expressiva). Me detenho mais especificamente no trabalho com a máscara neutra, objeto de minha investigação. Os exercícios ensinados com a máscara neutra foram os seguintes:

-o ponto fixo: partir do ponto zero (posição que consiste em ficar de pé, com os pés

paralelos e alinhados na linha dos quadris, cabeça ligeiramente inclinada para um ponto na frente/ nível baixo), ao sinal (nota musical produzida por um diapasão) olhar para um ponto à frente no nível médio, abrindo 
bem os olhos e transferindo, ao mesmo tempo, o peso do corpo para a região do metatarso. Afastar ligeiramente os braços do tronco. Esse lugar é chamado de ponto fixo. Depois, voltar para o ponto zero.

- ir do ponto zero ao ponto fixo e seguí-lo em seu giro de $180^{\circ}$;

- ir do ponto zero ao ponto fixo e dar um passo à frente;

- ir do ponto zero ao ponto fixo seguí-lo no seu giro de $360^{\circ}$;

- o despertar da máscara;

- roteiro de ações mais complexo;

- Triangulação/ assunto: ir do ponto zero ao ponto fixo/ dar uma volta de $180^{\circ}$ / olhar a platéia/ olhar o objeto (cadeira)/ dar um passo em direção ao objeto/ olhar a platéia/ olhar o objeto/ subir na cadeira/ olhar a platéia/ olhar o ponto fixo/ dar uma volta de $180^{\circ}$ / retornar ao ponto zero.

Os alunos foram ensinados a realizar o primeiro contato com a máscara sentados e de costas para a platéia. Deveriam, a princípio, se relacionar com o objeto (havia duas máscaras no chão, sobre um tecido, e pedaços de espuma à disposição para acertar a máscara no rosto): tocá-lo, olhá-lo, experimentá-lo, verificar qual das duas máscaras serviria melhor, experimentar com uma espuma no rosto. Depois disso, deveriam recolocar a máscara no chão, dar uma pausa, colocar o corpo em estado de repouso e então, colocar a máscara sobre a face. Deveriam pegá-la pelas laterais.

O corpo na neutralidade está em uma postura anatomicamente alinhada, move-se de forma simétrica, equilibrada, precisa agir com uma força superior à

utilizada no cotidiano, em tempo lento, o olhar deve ir de um ponto a outro de forma direta, sem vacilar, é necessário pôr pausas entre a chegada do olhar num ponto e a partida para outro ponto, as pausas não devem extrapolar três segundos. Apresento, a seguir, um resumo das idéias que foram veiculada oralmente:

- a neutralidade não tem nem futuro nem passado, não tem memória, tudo é novo e importante para ela;

- a máscara neutra desenvolve os sentidos que estavam impedidos pelo racional;

- a máscara se relaciona com o aqui e agora, cria um estado de calma e percepção;

- esse é um trabalho que busca a presença do ator; todo o corpo está em ação; 
- abandonar a gestualidade cotidiana é atingir a despersonalização;

- O método de ensino do grupo incluía:

- a máscara neutra não é nem alegre nem triste;

- a máscara deve estar sempre pronta para partir;

Explicação oral: antes ou depois dos exercícios os ministrantes realizam explicações orais sobre o que deve ser feito, colocando as regras do trabalho. Também passam uma teoria sobre o trabalho com a máscara, oralmente:

Demonstração técnica: antes dos exercício, geralmente a atriz Erika Rettl realizava uma demonstração técnica do trabalho;

Correções no corpo do aluno: através do toque, os orientadores posicionavam melhor o braço do aluno, a bacia, colocavam o corpo no eixo, etc...

Os ministrantes da oficina faziam avaliações orais após o exercício de cada aluno, explicando o que havia funcionado ou não no seu trabalho.

Através da prática com a máscara neutra no grupo Moitará, os alunos aprendem o seguinte: ter consciência corporal; ter contrôle corporal ( dominar a posição fundamental/ engajar o corpo como um todo na ação/ tonificar o corpo como um todo/ eliminar tensões/ controlar a direção do olhar/ pontuarSuma ação com a pausa, fazendo com que a ação tenha começo, meio e fim/ controlar sua respiração); trabalhar espontaneamente; ampliar a condição para observar e analisar o movimento; valorizar a percepção.

Crítica de resultado - Sobre o que se ensina e com que objetivos As regras

1. O ritual para colocar a máscara.

Os rituais estabelecidos são semelhantes no Grupo Moitará e em Copeau. Institui-se um caminho uniformizado, um ritual que propicia a concentração do aluno, a passagem de um tempo cotidiano ao "tempo da máscara"; uma mudança de tônus, de respiração;

2. Em cena, não tocar a máscara com a mão.

Regra colocada pelos ministrantes do grupo Moitará.

3. Não falar sob a máscara.

Segundo os ministrantes do Grupo Moitará, se o aluno falar sob a máscara sua voz não será projetada, irá sujar a máscara, estragá-la. Disseram ainda que isto seria anti-higiênico, visto que depois outro aluno iria utilizá-la. 
A marcação dessas regras foi constituindo um clima de respeito em relação à máscara, um respeito que ultrapassava a materialidade do objeto. Estávamos aprendendo a respeitar um objeto de forma quase sagrada, não no sentido religioso, mas por envolver algum mistério;

4. Não se aproximar da platéia.

para o chão.

regra presente no trabalho de Lecoq. Ele afirma que a máscara virada com o nariz para o chão ou, tocando o chão, é sinal de morte.

Uma regra funcional, presente no ensino do Grupo Moitará, para que a platéia tenha uma boa visibilidade do jogo.

1. Não tocar com a face da máscara no chão.

Não houve explicação para a regra no curso em Londrina. Verifiquei que é uma regra presente no trabalho de Lecoq. Ele afirma que uma mascara com o nariz virado, ou tocando o chão segnifica morte.

Os exercícios descritos por Chancerel (colaborador de Copeau), tais como direcionar o olhar, levantar, andar, em um estado de calma, guardam alguma semelhança com os exercícios propostos pelo grupo Moitará. Já os outros exercícios de figuração que eram feitos com máscara neutra na escola do Vieux-Colombier não têm nenhuma semelhança com a proposta do grupo Moitará. Assim, também os objetivos alcançados acabam sendo diferentes. Copeau, ao trabalhar com a figuração, leva o aluno a dominar a variação dinâmica do movimento.

\section{A noção de neutralidade e despersonalização}

Como explicitei anteriormente, Eldredge verificou que existem variações com relação ao conceito de neutralidade, que o "neutro" é uma construção intelectual e imaginária. Essa verificação nos permite afirmar que no Grupo Moitará, o que foi ensinado através da demonstração das atrizes como "a neutralidade" era "uma forma particular de se movimentar", um padrão de movimento desenvolvido no grupo. Estávamos aprendendo uma técnica corporal, mais especificamente, uma técnica corporal extra-cotidiana, pessoal. É uma técnica corporal por ser uma forma particular de utilizar o corpo; é extra-cotidiana porque necessita de uma aprendizagem mais ou menos formal; e pessoal por não ser feita pra ser vista, faz parte do treinamento do ator (VOLLI, 1985).

O conceito de despersonalização está relacionado ao conceito de neutralidade. São como duas faces da mesma moeda: para chegar a outro padrão 
de movimento (a neutralidade) eu preciso deixar de lado a minha maneira cotidiana de agir (a despersonalização). O conceito de despersonalização tinha o seguinte sentido, no grupo Moitará: "abandonar a gestualidade cotidiana é atingir a despersonalização". Em nenhum momento o conceito foi remetido à "possessão pelo outro" como propõe Lopes. Constatei que o grupo Moitará utiliza esse conceito no mesmo sentido que foi utilizado por Dullin (colaborador de Copeau). Ele afirmava que "despersonalizar" é mover-se sem seus tiques habituais, sem suas manias, tratando de compor os movimentos do exterior (DULLIN, 1946).

\section{A noção de percepção.}

Seria possível se relacionar com as coisas e os outros somente com os senti dos, sem pensar, como estava sendo proposta na oficina em Londrina? Isto é possível simultaneamente à aprendizagem da técnica? Recorri à psicologia científica como instrumento, a fim de elucidar o fenômeno. Constatei que o fenômeno da percepção é um fenômeno psicológico primário, acontece conosco.

Na percepção, estamos pura e simplesmente na contemplação do objeto, não há reflexão, noslimitamos em destacar uma forma sobre um fundo (...) esse modo irreflexivo é mais comum em crianças com menos de um mês de vida ou em casos de crise de esquizofrenia, onde a pessoa é levada pelos objetos que percebe, não pensa no que está fazendo. (...), não há como reconhecer uma personalidade estruturada numa pessoa absorvida nesse modo de relação com o mundo" (FRANCISCO, 1996).

Feito esse esclarecimento, fica evidente que não é possível uma pessoa, com sua personalidade estruturada, perceber (as coisas e os outros), sem pensar, durante os vários minutos que pode durar um exercício com a máscara neutra e tendo que organizar seus movimentos de acordo com regras precisas, como por exemplo: não ficar mais que três segundos em relação com o objeto. Ter que respeitar regras já é pensar. esse trabalho com a máscara neutra, podemos ter momentos de percepção sem reflexão, mas esses momentos são curtos visto que temos que estar atentos às regras que estamos aprendendo. $\mathrm{O}$ que seria possível é estar em relação com o objeto sem o posicionamento do eu para a consciência. Nesse caso, estaremos em uma relação espontânea com os 
objetos, o que não significa que não exista reflexão. O nome científico desse tipo de relação é consciência reflexiva espontânea. Constatei que essa questão está presente na pedagogia de Copeau: ele aborda o martírio do ator quando esse se ouve falar, se vê atuando, se julga.

O que é possível no trabalho com a máscara neutra, portanto, é construir uma figura neutra, que se relaciona com os objetos "como se" não tivesse nem passado nem futuro, "como se" não tivesse cultura. Essa figura neutra é uma construção a partir de uma idéia de neutro, de um padrão de movimento que buscamos e que chamamos de neutro. Com relação ao que foi ensinado no curso em Londrina, seria somente depois de o aluno dominar essa forma particular de se movimentar que ele poderia trabalhar sem o posicionamento do eu para a consciência, pois só depois de dominada uma técnica é que conseguimos nos mover na espontaneidade.

\section{Sobre como se ensina demonstração técnica}

Na oficina oferecida pelo grupo Moitará, geralmente uma das atrizes realizavauma demonstração antes de os alunos executarem cada exercício. A demonstração funcionava, inevitavelmente, de modelo aos alunos. Esse método difere do método proposto por Copeau, já que ele prescrevia a cópia do real e não a cópia do modelo.

\section{Direção expressa/ direção tácita.}

Constatei a presença dos dois tipos de orientação no trabalho realizado pelo grupo Moitará. A primeira é a "direção expressa": aquela em que o orientador diz ao aluno o que ele tem que fazer expressamente, detalhadamente. O outro tipo de orientação que verifiquei foi a "direção tácita" (ou implícita). Seguem alguns exemplos de "direção tácita": "acorde como se fosse pela primeira vez"; "siga seus impulsos"; "deixe que a máscara conduza você". Nesses casos os limites não estão claros. Não fica evidente para o aluno o que ele deve fazer exatamente. A orientação tácita sempre oferece uma abertura, permite a ultrapassagem de regras. Verifiquei que esse tipo de orientação torna-se complicado no trabalho com iniciantes na técnica, visto que um aprendiz não tem condições de ultrapassar o que ainda não domina. 


\section{A avaliação do aluno}

Identifiquei nas avaliações feitas pelos ministrantes do grupo Moitará momentos em que fazem avaliações objetivas e outros momentos em que a avaliação é subjetiva.

São exemplos de avaliação objetiva: "as oposições estão bem presentes"; "às vezes a cabeça finalizou o movimento e o corpo ainda não, falta precisão". ${ }^{2}$ Nessas avaliações, o ministrante está informando o que o aluno fez, mostrando quando ele realizou bem o exercício e quando não o fez. Constatei um exemplo de avaliação subjetiva quando o ministrante corrigiu um aluno que fez uma inclinação de cabeça: isto, "inconscientemente, é um estereótipo de doçura" " Há aqui uma interpretação do movimento por parte do ministrante. O movimento que o aluno faz é interpretado como revelação de algo que está oculto, que está em outro lugar, em uma suposta interioridade do aluno. Uma das conseqüências da avaliação subjetiva é que o aluno pode ficar confuso: o

\section{Considerações finais}

Nas considerações finais, foi possível constatar que o trabalho com a máscara o professor está avaliando o que ele traz inconscientemente ou o seu trabalho concreto, para verificar se está de acordo com o padrão de neutralidade? É possível que o aluno nem aprenda, se ficar preocupado com a doçura estereotipada que o professor diz que ele tem inconscientemente. neutra possibilita uma formação fundamental ao ator, porque ensina ao aluno um tipo de postura, de movimento e de relação deste com as coisas e os outros e que é suporte para qualquer construção de movimento, de personagem, de relação na cena. A neutralidade é um ponto de partida.

Verifiquei ainda que não há uma única forma de trabalhar com a máscara neutra, mas várias. Com as diferenças metodológicas também se alcança objetivos diferentes. Não há "um único" corpo neutro. O corpo que chamamos de neutro é um padrão construído a partir de certos princípios.

Pude constatar também que o trabalho com a máscara neutra não forma corporalmente apenas, mas prevê um engajamento específico da consciência. Com essa técnica, além de formar corporalmente o ator e de engajar a consciên-

2 FONSECA, Venício. Londrina. Transcrição de aula gravada em 31/05/2000.

${ }^{3}$ FONSECA, Venício. Londrina. Transcrição de aula gravada em 31/05/2000. 
cia, Copeau também preocupava-se em formar o "ator-sujeito". Além disso, a prática proporciona o conhecimento da relação eu/personagem.

Constatei por último que a maioria dos pedagogos sacralizam a máscara. Com base nessas considerações, levantei questões que merecem ser investigadas:

1. Se é possível trabalhar com e sem a sacralização da máscara, qual a função dessa variável no processo de ensino/ aprendizagem da máscara neutra na formação do ator?

2. Quais as conseqüências das seguintes proposições metodológicas para a formação do ator: expor regras sem explicar sua necessidade; solicitar que os alunos espectadores observem o trabalho do colega e façam uma avaliação objetiva; fazer uma avaliação subjetiva; fazer uma avaliação objetiva; ensinar com demonstração técnica, propondo a cópia do modelo; ensinar sem demonstração técnica?

Finalmente, termino a pesquisa esboçando algumas respostas provisórias:

Encontrar junto com o aluno a neutralidade.

Aponto como interessante a proposta metodológica de Eldredge: os alunos contemplam a máscara, falam sobre suas características, realizam com a máscara, ações simples. Observam e falam a respeito, procurando estabelecer o que seria uma movimentação tão neutra quanto aquela máscara. Digo que essa proposta é interessante porque viabiliza o aluno-ator- sujeito, sujeito na onstrução do novo padrão de movimento.

Com demonstração técnica, seria mais coerente utilizar a direção expressa.

Se utilizamos demonstração técnica, é importante conhecer que isso funciona como modelo para o aluno. É preferível esclarecê-lo de que essa é uma maneira de entender a neutralidade, que esse padrão de movimento foi construído. Sugiro ainda que se explicite o caminho que se fez para chegar no padrão. Porque no início o aluno vai aprender uma técnica, seria mais produtivo ser orientado apenas com direção expressa. Depois de dominada a técnica, poderia ser orientado com direção tácita, porque o aluno já teria o que ultrapassar.

Evitar o ensino formal de regras/ propiciar a avaliação objetiva. Se uma regra é ensinada sem explicação, o aluno respeita a regra em termos de certo/errado. Não há uma necessidade concreta do trabalho sustentando essa regra. Proponho que o professor aproveite a ocasião em que um aluno tenha tocado com a mão na máscara por exemplo, e pergunte aos alunos-espectadores: 
que efeito isso tem? Aprenderiam a falar do trabalho objetivamente, vendo as conseqüências para o espectador. Proponho que se aproveite a observação dos alunos-espectadores para o ensino de outras questões. Após um exercício, o professor poderia perguntar à platéia, por exemplo: quando um aluno movimenta-se de forma mais lenta, que efeito isso tem? E se fizer mais rápido, o que muda? Estaria assim evitando a interpretação sobre o que se passa na cabeça do aluno-ator, propiciando uma avaliação objetiva.

\section{Bibliografia}

COPEAU, Jacques. 1974. Registres I; Appels. Paris: Gallimard, 1974.

1993. Registres V; Les Registres du Vieux-Colombier III, 1919-1924. Paris: Gallimard.

CHANCEREL, Léon. 1944. Le masque (deuxième cahier). Prospero II. Paris: La Hutte, $\quad$ pp. 13-29.

DULLIN, Charles. 1946. Souvenirs et notes de travail d'un acteur. Paris: Odette Lieuter.

ELDREDGE, Sears A.; HUSTON, Hollis W. 1978. Actor training in the neutral mask. Drama Review, New York, v.22, n. 4, pp. 19-28, dec.

FRANCISCO, Paulo Roberto. 1996. Psicologia: Ciência e objeto. In: BERTOLINO, PEDRO et. Al. A Personalidade: Cadernos de formação. Florianópolis: Nuca Ed. Independentes.

LOPES, Elisabeth Pereira.1990. A máscara e a formação do ator. Tese (doutorado) Universidade de Campinas, Campinas (SP).

LECOQ, Jacques. 1988. Rôle du masque dans la formation de l'acteur. In: ASLAN, Odette. Le masque. Du rite au théâtre.Paris: Centre national de la Recherche Scientifique.

MARINIS, Marco de. 1995. Copeau, Decroux et la naissance du mime corporel.

Bouffonneries: Copeau l'éveilleur. "La cerisaie"/ Lectoure: Bouffonneries, $\mathrm{n}$. 34, pp. 127-143, 1995.

VOLLI, Ugo. 1985. Techniques du corps. In: BARBA, Eugênio; SAVARESE, Nicola.

Domaine de

Anatomie de l'acteur: Un dictionnaire d'anthopologie théâtrale. Lestanière: Bouffonneries Contrastes, pp. 113-123. 